\title{
Narrativa, subjetivação e enunciação: reflexões teórico-metodológicas emancipatórias
}

\author{
Valéria Marques de Oliveira \\ Universidade Federal Rural do Rio de Janeiro \\ Cecilia Raquel Satriano \\ Universidad Nacional de Rosario (Argentina)
}

\section{Resumo}

A narrativa enriquece a possibilidade do encontro do homem com a realidade, quer seja do mundo interior quer seja do exterior, e está presente na constituição do sujeito. Ao narrar, advêm à superfície elementos singulares e coletivos. Vista como um ato de subjetivação, favorece o processo de emancipação, como, por exemplo, em seu uso no empoderamento do sujeito nos campos da educação e saúde. A partir da reflexão crítica de pesquisas desenvolvidas no Brasil e na Argentina, integrantes do grupo de pesquisa "Atividades Simbólicas e Desenvolvimento Humano: foco em pessoas em situação de deficiência e em pessoas em situação de precarização simbólica e/ou risco social", propõe-se uma pesquisa básica, teórica, com foco nos conceitos de narrativa, subjetivação, enunciação e terapia. Como resultado, situando a narrativa como ferramenta teórico-metodológica, observou-se o encontro entre os referenciais argentinos e brasileiros que apresentam a relação entre narrativa e o processo de subjetivação e emancipação.

Palavras-chave: Enunciação. Narrativa. Empoderamento. 


\section{Narrative, subject forming, and enunciation: emancipatory theoretical/methodological reflections}

The narrative enriches the possibility of a meeting between man and reality, whether in the inner or outer world, and is part of the constitution of human beings as subjects. When one narrates, singular and collective elements come to surface. Seen as an act of forming subjects, it favors the process of emancipation, such as, for example, when it is used to empower subjects in the fields of education and health. Based on critical reflection on research performed in Brazil and Argentina by members of the "Symbolic Activities in Human Development: focus on people in a situation of deficiency and people in a situation of symbolic precariousness and/ or social risk" research group, what is proposed in basic, theoretical research, with a focus on the concepts of narrative, forming subjects, enunciation and therapy. As a result, situating the narrative as a theoretical-methodological tool, we observed the meeting between these Argentine and Brazilian references, which present the relation between the narrative and the process of subject forming and emancipation.

Keywords: Enunciation. Narrative. Empowerment.

\section{Narrativa, subjetividad y enunciación: reflexiones teóricas y metodológicas de emancipación}

La narración enriquece la posibilidad del encuentro del hombre con la realidad, ya sea en el interior o el exterior. Más que una práctica de la comunicación, está presente en la constitución del sujeto. Al narrar, llegan a la superficie elementos singulares y colectivos. La narrativa vista como un acto de subjetividad favorece el proceso de emancipación. Su uso se adapta a diversos fines, por ejemplo, el uso de la narrativa en el empoderamiento de los sujetos de la educación y la salud. A partir de la reflexión crítica de la investigación desarrollada en Brasil y Argentina, los miembros del Grupo de Investigación "Las actividades simbólicas y desarrollo humano: con especial atención a los niños en situación de discapacidad, de precariedad simbólica y/o riesgo social". Se propone una investigación básica, teórica, centrada en los conceptos de la narrativa, la subjetividad, la enunciación y la terapia. Al final, coloca la narrativa como una herramienta formal y metodológica. Hubo una reunión entre los puntos de referencia de Argentina y Brasil que muestran la relación posible entre la narrativa y el proceso subjetivo y la emancipación.

Palabras-clave: Enunciación. Narrativa. Empoderamiento. 


\section{Introdução}

O ser humano é o único animal capaz de construir uma narrativa. A internalização da realidade por meio da representação não é uma mera cópia, não replica o mundo externo dentro da mente, ela o relalpresenta, atualizado pelo filtro da percepção e da interpretação (Brockmeier; Harré, 2003; Bruner, 2001). Dotado de imaginação e criatividade, o ser humano transpõe a concretude da realidade com a sua construção mental, e, assim, transcende a mera reação à sensação e ativa o uso e a operação da representação mental. Esta concepção traz à tona a importância da conscientização e do compromisso político-social.

Uma forma de representação, função semiótica presente, por exemplo, na linguagem, aponta a condição humana de ser singular e coletivo, simultaneamente. A linguagem em relação estreita ao pensamento pode assumir um caráter pragmático, denotativo ou um caráter narrativo, conotativo. Ambos convivem e se enriquecem mutuamente, não são necessariamente excludentes. A linguagem na narrativa não é usada apenas para informar, mas também para diferentes tipos de ação, incluído o diálogo e a argumentação (Silva; Trentini, 2002). Pensa-se a palavra como um ato de subjetivação, e a narrativa insere-se nesta perspectiva. Visto que a narrativa expressa tanto os pensamentos e sentimentos singulares, assim como os significados sociais embutidos nos sistemas culturais e, em seu caráter conotativo, pode influenciar o processo de interação homem ambiente e sua própria constituição como sujeito, seu estudo é de real importância. Consideram-se todos os seres humanos possuidores desta habilidade narrativa, independentemente de sua condição.

O narrador, ao narrar, constrói e reconstrói, encadeia cenas e escolhe personagens, implica-se no narrado. Ele "escolhe" (conscientemente ou não) o que narrar e o que não narrar, atribui relevância e minimiza fatos, da mesma forma que pode trazer à tona uma determinada cena novamente. A partir da reflexão de sua própria realidade, o ser humano pode assumir com maior consciência que papel deseja ocupar em sua própria história. No ato de narrar, ele é impulsionado a ordenar os fatos e a atribuir-lhes sentido. Muitos fatores interferem nesta construção, a canonicidade é um dos elementos que provocam a manutenção do pensamento hegemônico e que enrijecem o pensamento por assumir valor de verdade imutável e impessoal. "Isto é assim, porque sempre foi assim e sempre será..." é um discurso que naturaliza a realidade e aniquila o caráter dinâmico da vida. Cabe destacar que não importa se o narrado refere-se ao acontecido ou à ficção (Fiorin, 2002), ele expressa fatores que influenciam a construção da realidade. Em contrapartida, a narração acompanhada da reflexão e elaboração é um exercício de autonomia e autoria de pensamento que colabora na emancipação. 
Considera-se que o ser humano tenha a possibilidade de fazer história em um lugar ativo de leitura da realidade e de exercitar seu poder de optar, negociar, transformar sua forma de ser e agir no mundo. Como sujeito histórico, que em suas ações e interações vai construindo os capítulos de sua vida, ele pode assumir um papel principal ou secundário na narrativa, ou até mesmo apenas uma figuração no discurso do outro. 0 trabalho com narrativa permite que a pessoa tome consciência de si e do mundo, neste processo de construção, e decida com maior responsabilidade o lugar que deseja ocupar em sua própria história. A posição assumida vai interferir não apenas na qualidade da própria vida, mas também na qualidade de interação com os outros. (De Conti; Sperb, 2009; Greco, 2006; Carvalho, 2004)

Contudo, a narrativa é um recurso útil não apenas na intervenção social e na psicoterapia, mas também no ensino e na pesquisa (Nunes; Castellanos; Barros, 2010). Além de poder provocar mudanças em quem narra, tem sua extensão de influência também em quem ouve a narrativa. Possuidora de grande riqueza de aplicabilidade, a narrativa se insere como uma técnica da pesquisa qualitativa que pode ser utilizada sozinha ou dentro de uma combinação de outras técnicas, considerada uma forma de entrevista não estruturada. 0 interesse de estudo sobre este tema, dado o seu caráter interdisciplinar, reúne pesquisadores de diferentes áreas e de diferentes tendências, psicólogos sociais, sociólogos, linguistas, historiadores, antropólogos, médicos, enfermeiros etc., cada qual com um direcionamento próprio (Joutard, 2000). A escolha pela interdisciplinaridade destacou-se a partir dos anos 80 e fortaleceu o uso da narrativa como ferramenta metodológica.

Nesta perspectiva, o grupo de pesquisa “Atividades Simbólicas e Desenvolvimento Humano: Foco nas Pessoas com Necessidades e/ou Risco Social" tem se debruçado sobre o estudo da narrativa como uma de suas atividades. Este grupo pesquisa as questões simbólicas sobre o ser humano em condições especiais de desenvolvimento, frequentemente excluído socialmente, com foco nas pessoas com necessidades especiais (ênfase em pessoas com deficiência intelectual), nas pessoas em risco social e/ou nas pessoas idosas com comprometimento cognitivo orgânico, descritas pela literatura com predominância no campo da debilidade, deficiência ou degeneração.

Eleger o uso da narrativa para a discussão a respeito desta população significa estar associado à perspectiva sócio-histórica, que não se submete à interpretação circunscrita à condição individual predeterminada e descontextualizada. Emerge também, nesta escolha, a conceituação de precarização simbólica, que se refere à falta de investimento tanto libidinal quanto educacional e suas consequências para a constituição do sujeito. Logo, neste grupo de pesquisa, há um compromisso 
ético e epistemológico com a emancipação e rompe-se com a visão paternalista e assistencialista do desenvolvimento humano.

Duas pesquisas deste grupo - "Intervenciones con niños en contextos de precarización simbólica”, coordenada pela Profa. Cecilia Satriano (UNR/ Argentina), e "Educação inclusiva junto ao aluno com deficiência cognitiva no primeiro ano do ensino fundamental na cidade de Resende", coordenada pela Profa. Valéria Marques (UFRRJ/Brasil) -, em diálogo, desencadearam a demanda pela organização de um corpus teórico comum. A elaboração deste artigo, que tem como motivação os resultados experienciados em ambas as pesquisas, teve como ponto comum a precarização simbólica e seu efeito na constituição do sujeito. Delineou-se a necessidade de sistematização da fundamentação teórica referente à narrativa, que embasou cada pesquisa e possivelmente conecta ambas as proposições, verificando a viabilidade de sua articulação e a emergência de uma matriz teórica comum.

No encontro entre estas investigações, mais do que o estudo sobre a função da narrativa, há o interesse em como ela é produzida e o que ela produz. Desta forma despontam os questionamentos: Qual é o lugar enunciativo ocupado pelo sujeito? Ele se apresenta como autor, narrador ou personagem? Protagonista ou figurante? Mantém-se como objeto de desejo do outro, como sujeito do enunciado ou como sujeito da enunciação? Ele se reconhece em sua narrativa ou nem se percebe como sujeito? Como se apresenta a narrativa? Que elementos a compõe e que efeito causa? Estas questões provocam profundas inquietações, que são importantes não apenas quando chegam a uma conjectura interpretativa, mas pelo próprio processo de construção que reverberam no pesquisador.

Para aprofundamento das questões emergidas da interseção destas pesquisas, este trabalho propõe um recorte conceitual sobre narrativa. Opta, como metodologia de trabalho, pela pesquisa básica, teórica, na qual se verifique a possibilidade do diálogo e da organização de proposições psicodinâmicas utilizadas pelas referidas pesquisadoras no que tange à fundamentação do uso da narrativa como enunciação, fator de empoderamento. As investigações empíricas foram desenvolvidas junto às crianças em situação de deficiência e/ou risco social, ambas com características de precarização simbólica, e serviram como base de ilustração empírica dos conceitos-chave articulados. Estes conceitos são analisados e se apresentam, ao longo do texto, fruto de uma construção conjunta das autoras. Como operador de ação, manteve-se como palavra-chave: narrativa, e como desdobramento suas articulações: narrativa e subjetivação, narrativa e enunciação, e narrativa: teoria e terapia. 0 texto segue esta organização e, ao final, visa à organização possível de uma matriz teórica que sustente pesquisas narrativas futuras. 


\section{Narrativa}

A narrativa, como uma forma de representação, desvela a condição humana do ser histórico e social, visto que a vida é uma construção de quem vive em consonância com seu contexto. Ela consiste em contar acontecimentos numa sequência estruturada que possibilita a compreensão do ocorrido. Algumas características específicas são: al envolvimento de qualquer tempo e espaço: mítico, histórico, vivido; b) descrição de acontecimentos que podem ou não envolver diferentes pessoas, objetos e animais, c) relato de fatos ocorridos ou imaginados, d) campo de elaboração de conteúdos pessoais, el sequencialidade singular e f) abertura a uma nova narrativa. 0 que todas estas possibilidades têm em comum é que compõem um canal de expressão do mundo interno do sujeito. Este aspecto torna-se diferencial quando dirigido principalmente para a população de pessoas com precarização simbólica, quer seja da pessoa em situação de deficiência quer seja da pessoa em situação de risco social. 0 exercício da narrativa dirige a pessoa para sua condição de sujeito, autor e ator de sua história, independentemente de sua condição educacional ou socioeconômica.

Narrativa é uma tradição de contar um acontecimento em forma sequencial, cuja composição mais simples inclui começo, meio e fim, e tem, em sua estrutura, cinco elementos essenciais: o enredo (conjunto de fatos); as/os personagens (quem faz a ação); o tempo lépoca em que se passa a história, duração da história); o espaço (lugar onde se passa a ação) e o ambiente (espaço carregado de características socioeconômicas, morais e psicológicas onde vivem as/os personagens). (Silva; Trentini, 2002, p. 425)

Ao assumir o lugar de narrador, ativa-se a organização e estruturação psíquica colorida por elementos pessoais e coletivos que pode ser utilizada para a emancipação. Ao narrar, forma-se uma rede de significações que marcam o estilo do narrador, a hermenêutica está presente nele e no seu interlocutor. Neste espaço, há possibilidade de troca e crescimento não apenas pessoal, mas mútuo. Costa (1993) destaca na obra de Barthes a questão do tempo lógico e realça a relação negociada do significado e não apenas a lógica natural do narrado, quebrase mais uma vez o real e abre-se para o simbólico e o imaginário.

A narrativa é, pois, uma estrutura, um sistema de unidades e regras que geram significação. Sua sintaxe se organiza por uma lógica própria, intemporal, diferente do tempo real e cronológico. 0 tempo real não pertence ao discurso, mas ao referente. Falar do tempo verdadeiro no discurso é falar de uma ilusão referencial de marca realista. (Costa, 1993, p.28) 
Nas últimas décadas, observa-se um movimento de resgate e de reafirmação da importância da subjetividade na psicologia enquanto ciência. A teoria narrativa, pela riqueza de sua diversidade epistêmica, contribui neste caminhar, e a narrativa desponta como um caminho rico e promissor. Como seu estudo, originalmente, pertence à linguística, antes de tudo, deve-se justificar o estudo e o uso da narrativa como uma ferramenta dentro do campo da psicologia. 0 tema subjetividade na psicologia é um divisor de águas, e a narrativa resgata o valor da singularidade e dos processos de subjetivação.

Uma mesma narrativa pode ser estudada a partir de diferentes características e com diferentes objetivos, que podem se articular entre si. Adentrando numa visão interdisciplinar da narrativa, a leitura sobre as condições linguísticas, por exemplo, torna-se uma categoria de leitura útil para outros diferentes campos de saber, em que se destacam três condições determinantes: 1) psicológicas presentes na codificação e decodificação; 2) culturais relacionadas ao conhecimento, e 3) ideológicas formativas do sistema de interpretação. Busca-se neste texto enaltecer a leitura psicológica numa perspectiva interdisciplinar.

A estrutura de uma narração é semelhante à estrutura de orientação para a ação: um conceito é dado; os acontecimentos são sequenciais e terminam em um determinado ponto; a narração inclui um tipo de avaliação do resultado. Situação, colocação do objetivo, planejamento e avaliação dos resultados são constituintes das ações humanas que possuem um objetivo. A narração reconstrói ações e contexto da maneira mais adequada: ela mostra o lugar, o tempo, a motivação e as orientações do sistema simbólico do autor. (Bruner, 1990 apud Jovchelovitch; Bauer, 2002, p. 92)

Pesquisar sobre narrativa aponta para o reconhecimento do outro como diferente e semelhante simultaneamente. Diferente, visto que somente ele pode enunciar seu mundo interior e sua forma própria de leitura de mundo. Semelhante, visto que ambos, narrador e interlocutor, devem compartilhar de sistemas de interpretação capazes de negociação de significados. Outrossim, valorizar a narrativa de uma pessoa em situação de deficiência intelectual, por exemplo, representa o reconhecimento dela como sujeito e a riqueza de significações carregadas de conceituações e sentimentos no material trazido. Reconhecer o valor da narrativa abre a possibilidade para a interlocução, mesmo que imaginária, entre narrador e narratário.

Patron (2006) propõe o estudo da narrativa como ficção e não como comunicação ou expressão de verdade. Esta posição liberta o entrevistador do papel de "investigador policial" e facilita o seu lugar enquanto interlocutor, como copartícipe desta narrativa, engrandecendo o valor da interpretação. Mesmo com o uso 
exaustivo da retroalimentação, isto é, da pergunta e resposta "esclarecedoras", não se pode garantir a exatidão, a certeza, a objetividade, porque a narrativa é, em si própria, fruto da subjetividade, da ambiguidade, de uma intenção de encontro último do narrador até mesmo consigo próprio.

Um pressuposto básico a ser delineado, portanto, é que não há uma verdade plena a ser descoberta e, sim, a busca para aproximar a leitura de verdades parciais e temporárias. Para Fiorin (2002, p. 32), “a narrativa é um simulacro das ações humanas e uma teoria narrativa é, antes de mais nada, uma teoria de ação". Ela é uma forma universal de expressão da experiência humana, encontrada em todas as culturas, podendo ser oral ou escrita (Silva; Trentini, 2002; Jovchelovitch; Bauer, 2002). As narrativas são constelações transitórias (flutuantes) de formas de vida mais bem entendidas como padrões fluidos de ação e posicionamento e são consideradas como modus operandi de práticas discursivas específicas relacionadas aos textos e contextos culturais. (Brockmeier; Harré, 2003)

Por isso, a narrativa traz a possibilidade da reflexão, da autoconsciência e da interlocução. Ela vai ao encontro da valorização da psicodinâmica existente tanto nos processos singulares quanto nos processos sociais simultaneamente, ou seja, conjuga a identidade pessoal e social no que concerne à riqueza simbólica existente. Nesta trama, a cultura é destacada como um dos constituintes do sujeito (Silva; Trentini, 2002). Ao trabalhar com a narrativa de uma criança de classe socioeconômica muito desfavorecida, em contextos de precarização simbólica, simultaneamente se analisa o que aparece de singular em sua narração e o que aponta para sua contextualização espaçotemporal. Quando esta criança narra sua origem e a história de sua família, por exemplo, tem a oportunidade para se descolar do discurso opressivo estereotipado, para, em contrapartida, fortalecer sua saúde psíquica e sua identidade pessoal e social. Ela experiencia o deslocamento do destino imutável e já conhecido de um contexto a que se submete para outros operadores que favorecem a atividade e a mudança.

0 aprofundamento do embasamento teórico sobre narrativa, quando caminha junto ao embasamento metodológico, permite captar o movimento, a história, o processo, a percepção e a (re)construção da realidade de ambos os atores sociais: o narrador e o narratário. Trabalhar com narrativa implica, portanto, considerar sempre a relação, mesmo que seja o narrador com seu Outro. Por conseguinte, trabalhar com narrativa implica considerar a ambiguidade, a polissemia, a complementariedade e o processo. 0 narratário igualmente também não é neutro, está igualmente entremeado na narração da mesma forma que o narrador, visto que é impossível separar interpretação e narrativa. Esta argumentação traz outra contribuição para a formação de pesquisadores no âmbito da narrativa, a observação de segunda ordem, isto é, a observação de si 
próprio além da observação do sujeito de pesquisa. Isto pode ser operacionado por meio da autorreflexão acerca dos registros nos cadernos de campo (diário de bordo, cadernos de pesquisa, etc), no qual são anotados, além da descrição do observado, as percepções e os sentimentos despertados no pesquisador. Estes registros são analisados posteriormente tanto de modo amplo como de modo relacional às transcrições/registros das narrativas. Neste encontro entre narrador e narratário/interlocutor que fatores os aproximaram ou os afastaram? Houve algo que pudesse interferir (positiva ou negativamente) neste evento? Qual clima prevalecia no momento da coleta de dados? Os elementos encontrados são alvo de análise como todo material coletado.

Bruner (2002) disse que narrativas são ferramentas para domar o estranho, ou seja, por meio destes, recebemos explicações sobre os novos eventos. Neste sentido, a narração não é um esquema primário de pensamento, nem mesmo uma sucessão particular de eventos organizados em um quadro. Este autor contribui para o estudo da narrativa em diversos aspectos, um deles é sua diferenciação entre o pensamento lógico-matemático, paradigmático, e o pensamento narrativo, capacidade de produção de história das histórias. Ao narrar histórias, constróise um significado pelo qual as experiências fazem sentido. Se o pensamento paradigmático é o comum, o estabelecido, o já conhecido, o pensamento narrativo advém do que é especial, caracteriza-se por sua abstração, que surge a partir das imagens que aparecem na forma não linear, mas analógica. 0 diálogo entre 0 narrador e o narratário/interlocutor é fruto de negociação: para que haja o encontro eles devem compartilhar um espaço de criação. Aplicando esta argumentação a um campo empírico, significa dizer que um pesquisador que interprete narrativas sem contextualizá-las poderá saber algo sobre si próprio, mas nunca sobre o narrador. Ao trabalhar com criança de periferia cujos pais trabalham fora, que convive durante todo o dia com seus pares apenas, a interpretação da queixa escolar de dificuldade de aprendizagem não pode se reduzir à falta de acolhimento parental, por exemplo. Vários elementos podem estar influenciando este comportamento infantil, a narrativa desta criança pode revelar elementos desconhecidos anteriormente se o pesquisador estiver aberto para tal. A interpretação passará pelos aspectos espaço-temporal e sóciocultural, para citar alguns.

Outro autor que contribuiu com o estudo sobre o uso das narrativas é Guidano, um dos terapeutas mais influentes do Construtivismo hoje (Ruiz, 2007). 0 problema mais importante da perspectiva construtivista é a maneira de conceber a relação entre o observador e o observado. Guidano (1994) relaciona as imagens produzidas nas histórias com a própria vida, estão relacionadas ao sentido. 0 senso de self corresponde à coerência interna desta história de vida única, em que o sujeito é o personagem principal, que se interpreta e vive todos os dias. 
Feita esta primeira explanação sobre questões básicas da pesquisa narrativa, em seguida serão apresentados conceitos articulados à narrativa: subjetivação, enunciação e relação entre teoria e prática.

\section{Narrativa e subjetivação}

Como visto anteriormente, o ato de narrar é exclusivo do ser humano para dar sentido a sua experiência. É um relato de um acontecimento com relação de anterioridade e posteridade, entremeado de elementos conscientes e inconscientes, que permite ao narrador (re)interpretar sua vida e atribuir uma significação pessoal à realidade dentro de um contexto social maior. Esta operação pode ser aprendida, visto que nem todos parecem “ouvir a si próprios". No trabalho com pessoas com deficiência intelectual, por exemplo, muitas vezes estas pessoas são "faladas" por outras que antecipam sua fala e lhes resta apenas o lugar de objeto do discurso e não de narrador. Mesmo em algumas situações, quando "narram" alguma cena, estas pessoas, quando em condição de opressão, apresentam uma narrativa pobre, repetitiva, estereotipada. Se estas pessoas são interrompidas em sua narrativa, elas retornam a algum ponto anterior tal qual "um disco arranhado". Infelizmente, na maioria das vezes, esta situação não causa ao seu interlocutor um espanto, por já antecipar que aquela pessoa naquela condição somente teria esta produção. Isto é uma distorção. A narrativa exige do narrador um nível de implicação que pode ser maior ou menor. Esta narrativa tem em si um objetivo que também interfere nesta implicação. Pode-se argumentar que uma narrativa possa ser mais rica em elementos do que outra, mas todas as narrativas revelam algo de seu narrador. Somente por este fato, nenhuma narrativa é realmente pobre, já que ela pode servir de canal para algo único, o sujeito. Seguindo esta argumentação, diferentes modalidades de emprego dos métodos narrativos afirmam que os sujeitos proporcionam uma "visão interior da pessoa", porque as tratam como "testemunhas especializadas" ou "peritas" nos assuntos de suas próprias vidas.

A narrativa traz a possibilidade da reflexão, da autoconsciência, fruto da subjetividade, da ambiguidade e de uma intenção e ilusão de encontro. As palavras depois de proferidas não mais pertencem somente ao seu autor, elas são resultado de pelo menos dois, narrador e interlocutor, em relação ao contexto, canal de comunicação expressão, momento de vida e etc.

Relacionado à possibilidade de emergência do sujeito na narrativa, Greco (2006) alarga a discussão acerca da constituição da identidade e a propõe não como fruto meramente individual, mas como construção conjunta do coletivo. Ele 
compreende a subjetivação como a relação de um si mesmo com outro, a busca permanente de um nome, de um nomear-se a si mesmo em relação a outros. Em sua argumentação, ela se utiliza da diferenciação entre a violência primária, fundante, importante na constituição do sujeito, e a violência secundária, que não favorece a transformação. No primeiro caso, o sujeito emerge na língua, ele pode assumir sua voz; na segunda, o sujeito é falado, ele não tem direito à sua própria voz.

A autora aponta a influência na constituição do sujeito, sua possibilidade de ser diferenciado, nos espaços e lugares compartilhados intergeracionalmente, intersubjetivamente. Na transmissão de uma herança, de uma cultura, presentificase o laço que une o individual e o social. Destaca que a influência não se reduz aos laços primários, às funções maternas e paternas, mas também à influência de outros adultos-referência em diferentes funções e em diferentes espaços sociais e institucionais.

Ela utiliza a narrativa de um menino sobre si mesmo para ilustrar como se podem obter informações importantes sobre a situação escolar vivida. Contrapõe-se aos relatos dos profissionais sobre a mesma situação, os quais apareciam enviesados com a produção de julgamento deles, e com poucos dados sobre a singularidade e/ou emergência do sujeito. Nestes relatos, eles já o descreviam de modo que formatavam o rótulo de "menino problema" como parte de sua existência - "ele é" -, diminuindo ou dirimindo suas possibilidades de ser diferente da expectativa dada. No autorelato, abriu-se a possibilidade para a reflexão e uma nova escrita.

Em seu processo de constituição de sujeito, ele se defronta com o projeto identificatório no qual constrói um saber sobre o eu futuro e sobre o futuro do eu. Uma conjectura sem certezas, apenas direções e apostas, possibilidades. Seu objeto em uma imagem identificatória é valorizado tanto pelo próprio sujeito quanto por seu entorno social. Os três tempos presentes: presente-passado, presentepresente e presente-futuro se atualizam na narrativa. Estes fatores podem ser observados quando a criança pode enunciar: "quando eu for grande, eu ..." e quando mais tarde ele diz, “... serei isto” (Greco, 2006). Conjugar o tempo futuro no projeto identificatório é garantia de sustentação do eu; é preciso conectar o que se é e o que se pode ser, projetar-se no futuro para sustentar a identidade atual e a futura. 0 futuro não pode coincidir plenamente com o que já se tem, com o já conhecido, com o risco de não se caminhar, de se aniquilar o desejo. Algo mais é preciso, um vazio, uma meta a ser alcançada. Este descompasso entre o presente e o futuro não pode ser inalcançável.

Considera-se tanto a noção de infância quanto a constituição de sujeito como conceitos dinâmicos que negociam seus sentidos permanentemente. Portanto, esta é a fratura que se propõe, criticando uma visão fatalista de lesão ou "marca de 
nascença", uma noção de identidade e de personalidade fixa colada ao indivíduo.

O sujeito do enunciado refere-se ao significado, ao discurso consciente, representante do discurso social, do discurso manifesto. 0 sujeito da enunciação refere-se ao significante, ao discurso inconsciente, representante do excêntrico em relação ao sujeito do enunciado (Jorge, 2002). É nos deslizes dos significantes que advêm as formações do inconsciente (sonhos, chistes, atos falhos, sintomas, etc.). Neste texto, quando se aponta o sujeito, aponta-se para o sujeito do inconsciente, sujeito do desejo. Este sujeito não se iguala ao "eu", ele surge da fratura, do espaço que escapa, do efeito que resulta da discordância entre enunciado e enunciação. Este sujeito desejante busca não apenas satisfazer necessidades, mas demanda amor, clama por ser reconhecido. 0 sujeito advém pela linguagem, contudo isto não significa ficar aprisionado ou programado por ela. 0 sujeito está no terreno da representação, campo de articulações de significantes, campo em atualização constante. É na palavra que o sujeito encontra sua articulação fundante (Dor, 1989). A cadeia simbólica marca o homem antes de seu nascimento e mesmo depois de sua morte. Quando alguém nasce, já se encontra marcado no discurso, no qual se inscrevem as fantasias paternas, as crenças e valores, a cultura e as demais características do contexto espaço temporal. Assim sendo, o sujeito do inconsciente e do desejo está no nível do sujeito da enunciação e não do enunciado. 0 sujeito do enunciado designa o sujeito da enunciação, mas não o significa.

0 sujeito não chega à completude, nem este pode ser seu objetivo, ele é barrado e se constitui no processo, nas negociações internas e com seus interlocutores. A própria emergência de negociação aponta para a saída do lugar de objeto e a emergência do lugar de sujeito. Negociação só ocorre entre sujeitos, entre mundos simbólicos. Na narração, o sujeito pode confrontar-se em seu discurso e perceber que lugar ocupa e de que modo. 0 sujeito pode assumir diferentes perfis: pode ser o narrador, pode ser um personagem protagonista ou pode até mesmo estar ausente, perdido no discurso de Outro.

A criança, ao nascer, insere-se em uma história familiar e tem direito ao acesso à herança intergeracional. Ela necessita de alguém que conte a história de sua origem, de sua vida, além de nomear os eventos que a circundam. A sua posição enquanto autora de sua história dependerá desta dinâmica, “ou seja, somente se apropriando da sua herança intergeracional é que o sujeito pode transformar, ressignificar a sua história e não somente reproduzir a história oficial". (De Conti; Sperb, 2009, p. 120)

As crianças em contextos de precarização simbólica têm maior probabilidade de encontrar dificuldade nesta empreitada. Seus resultados serão possivelmente deficitários quer seja por questões vinculares afetivas, como, por exemplo, a falta de um interlocutor que demande e sustente a narrativa; quer seja por questões 
sociais, como, por exemplo, a falta de eventos capazes de mobilizar o desejo de narrar; quer seja por questões cognitivas, como, por exemplo, a pobreza de vocabulário e de conceitos que componham a narrativa. (Marques; Satriano, 2009, 2010)

Segundo Alves, Rabelo e Souza (1999 apud Vasconcelos; Fontenelle; Nations, 2003), a assunção ativa pela sua própria vida advém do problematizar a experiência, e, como viver é dinâmico, sua compreensão não pode ser deduzida de um sistema linear, coerente e ordenado de ideias, símbolos ou representações. 0 pulsar é inerente ao viver, a imprevisibilidade e a flexibilidade são condições imprescindíveis para a saúde. Para os autores, a experiência não pode ser reduzida a um conjunto de significados, visto que eles são sempre do campo do parcial e inacabado de uma realidade mutante e dinâmica. Os significados são frutos de representações (re)formuladas constantemente em um processo de negociação no diálogo com outros. 0 estudo da narrativa, portanto, não almeja a reconstituição exata de dados, não é uma investigação policial que alimentará um julgamento. Sua valorização está na representação e na negociação da significação. “A negociação é a arte de construir novos significados pelos quais os indivíduos podem regular suas relações uns com os outros". (Bruschi; Guareschi, 2007, p. 1)

A narrativa é plástica e permite inúmeros arranjos e utilidades. Ela pode ser mais estruturada ou menos estruturada, mais consistente (em relação ao real) ou mais fantasiosa. Mais do que simples descrição, a narrativa configura-se no campo da elaboração. 0 narrador, ao dirigir sua narrativa, tem a possibilidade de (re)encontrar-se com a realidade e organizá-la (Dutra, 2002; Silva; Trentini, 2002). Não basta o simples relato, mas o trabalho de (re)construção do narrado. Esta ação exige cuidado no manejo para que não sejam criadas "memórias falsas" que alimentem fraturas maiores. Dutra (2002) afirma que esta reconstrução de sentido é possível graças à abertura que constitui o ser em sua existencialidade.

Segundo Dutra (2002) a narrativa vem como possibilidade de colaborar no reconhecimento da riqueza simbólica de cada um, momento existencial da pessoa, consciente ou não, mas que influencia seu estar no mundo. No intercambiar de experiência eclode a possibilidade de assunção do destino de sua própria vida, (re)escrevendo sua caminhada, criando um espaço-tempo para reinterpretar o passado, refletir o presente e projetar o futuro (Silva; Trentini, 2002; Labor, 1997 apud Vasconcelos; Fontenelle; Nations, 2003). Dada a possibilidade de reconstrução permanente, cada narrativa é única, Benjamin a legitima como expressão de uma dinâmica fenomenológica existencial (1994 apud Dutra, 2002). Dutra (2002, p. 374) supõe que 
[...] de certa maneira, o ato de contar e ouvir uma experiência envolve um estar-com-nomundo, uma relação de intersubjetividades, que se dá num universo de valores, afetos, num passado que se articula com o presente e apoiado numa situação que reflete, revela, conserva e transcende o mundo em que esses personagens estão inseridos.

Esta discussão se entremeia com a concepção de emancipação. “nadie puede ser emancipado por otro pero a la vez, nadie se emancipa solo (Greco, 2006, p. 141 “ninguém pode ser emancipado por outro, mas, também, ninguém se emancipa sozinho - tradução livre).

Em consonância com a discussão da concepção de sujeito apresentada, a emancipação se dá tanto individualmente quanto coletivamente, em processos pessoais e políticos descobertos ou inventados. 0 processo emancipatório é compreendido como trabalho de humanização (Greco, 2006). 0 sujeito emancipado não preexiste, ele demarca um processo, um constituir-se. A emancipação não é um estado final ou um produto alcançado, aponta para o movimento emancipatório. Este movimento está presente na enunciação.

\section{Narrativa e enunciação}

A democracia e a cidadania são experiências construídas internamente, um exercício de consciência política, e não são frutos diretos da titulação acadêmica ou do acúmulo de capital. Infelizmente, ainda se observa uma discrepância entre o propagado e promulgado nas letras da Lei e o vivido no cotidiano.

Em especial no Brasil, a memória histórica e a participação civil se apresentam frágeis, fato que pode ser comprovado no cotidiano desde o silêncio sobre escândalos econômicos e políticos até o esquecimento dos candidatos votados em uma eleição, logo que esta termina. Este comportamento parece revelar fortes marcas da própria história do povo, oprimido desde o início, quando exploradores invadiram o País e denominaram este feito como "descoberta", em nome de um bem religioso e social. 0 massacre dos índios e dos estrangeiros ingressos como mão de obra barata no Brasil (escravos africanos e imigrantes) transparece na conduta de subserviência e idolatria do capital (econômico e cultural) exterior, comportamentos resultantes da opressão vivida. A desigualdade econômico-social ainda é muito discrepante no País, com reflexos diretos na qualidade dos serviços sociais, educacionais e da saúde. Contudo, o quadro não é apenas de resignação e subserviência, visto que o que antes era propagado com cunho pejorativo - a mestiçagem e a cultura advinda deste encontro - na atualidade é considerado uma qualidade peculiar, encontrada na habilidade de atualização, criatividade, 
resiliência, própria do brasileiro. (Damatta, 2000; Joutard, 2000)

A escolha pela narrativa no processo de enunciação tem como meta implícita o empoderamento da pessoa e do grupo. Quando as pessoas conversam mais, quando compartilham mais espaços sociais (quadras, clubes, praças etc.), ampliase a possibilidade da interlocução, da identificação e da organização sociopolítica. A narrativa é o ato da enunciação e influencia a ação libertária em diferentes campos: social, educacional e da saúde. 0 humano é visto em sua plenitude e não reduzido unicamente ao aspecto racional, já que os aspectos afetivos e sociais são igualmente importantes. Em rodas de conversas, há a possibilidade de atualização de percepções e quebra ou não de preconceitos. Num ambiente escolar, no qual um professor não tenha consciência de seu preconceito, em sua mediação ele pode favorecer a consciência e emancipação de sua classe, ou muito pelo contrário, exercitar o monólogo e o exercício da obediência cega dos estudantes. Isto pode ser exemplificado na descrição feita por um professor acerca de uma aluna descrita como desinteressada e desinteressante, inábil e incapaz. Esta aluna mostrava-se apática e relutante a qualquer troca social. Após um trabalho com a turma no qual cada um deveria apresentar sua história e suas preferências, esta estudante surpreende a turma ao fazer um autorelato com uma história pessoal carregada de perdas afetivas. Após a intermediação da pesquisadora que estudava o processo de construção do conhecimento, a estudante reconhece em si a habilidade e o domínio do corte e costura. Houve uma reorganização grupal, e não apenas esta estudante conseguiu romper com a imobilidade, todos passaram a "ouvir e ver" o outro e a si próprio de modo mais efetivo. Não se apaga o passado, mas pode-se aprender com ele.

A descoberta e o reconhecimento da riqueza natural e cultural do brasileiro, por exemplo, são vistas cada dia mais em ações ainda incipientes, mas de grande impacto, tais como desenvolvimento sustentável de comunidades, crescimento de grupos étnico-culturais com orgulho de sua origem etc. Os movimentos sociais libertadores estão ganhando corpo e se organizando cada vez mais. Estes ainda não capazes de mudanças drásticas, porém, mesmo que em algumas comunidades apenas, estão adentrando no imaginário social de modo positivo.

Diferentemente do depoimento, a narrativa não pretende informar ou explicar nenhum fato (Dutra, 2002). Manovich (2001 apud Souza, 2010) distingue narração e descrição, a primeira traz um enredo com movimento, e a segunda traz distanciamento e passividade. A narrativa oferece a evidência dos significados subjetivos, fruto de construção, incorporação ou submissão de um modelo cultural.

A narrativa traduz o conhecimento objetivo e subjetivo do mundo lo conhecimento sobre a natureza física, as relações humanas, as identidades, as crenças, valores e mitos, 
etc.) em relatos. A partir dos enunciados narrativos somos capazes de colocar as coisas em relação umas com as outras em uma ordem e perspectiva, em um desenrolar lógico e cronológico. É assim que compreendemos a maioria das coisas do mundo. (Motta, 2005, p. 2)

Cabe a distinção de dois conceitos aos quais correspondem duas ideias interligadas: narrativa e narratividade, respectivamente, produto final e seu processo de formação de sentido.

A narratividade é, radicalmente, um ato de configuração do sentido variável de ações e paixões; ações e paixões que podem estar organizadas do ponto de vista da forma do seu conteúdo, ou seja, de sua semântica, e podem ser manifestadas por uma forma de expressão distinta (verbal, gestual, música etc.). (Fabbri, 2000, p. 57-58 apud Souza, 2010, p. 43)

A narratividade como processo enunciativo baseia-se em duas teses centrais “(a) o discurso, embora obedeça às coerções da estrutura, é da ordem do acontecimento, isto é, da História e (b) não há acontecimento fora dos quadros do tempo, do espaço e da pessoa". (Fiorin, 2002, p. 14)

Para Van Dijk (2008, 1973), a narrativa é uma das faculdades cognitivas e, mais especificamente, semióticas do homem. Elas são formas básicas de comunicação cotidiana, em primeiro lugar. A pessoa que fala pode ou não se envolver, mas o que se considera é o contexto do que é narrado, as descrições de circunstâncias e eventos que compõem a história. Este autor discute o poder no discurso. 0 fortalecimento do poder se dá não só pelo acúmulo de riquezas, mas também pelo de saber. Cientes disto, aqueles que o detêm controlam o seu fluxo tanto em relação à forma, quanto à qualidade e ao modo de distribuição da informação; a isso entenderemos como abuso de poder. Essa forma de abuso de poder, a partir da manipulação, doutrinação e desinformação, também é responsável por intensificar a desigualdade e injustiças sociais. Na narrativa podem-se identificar elementos que se prestam a manter o poder hegemônico e opressor, tais como encontrados em ditados populares: "pau que nasce torto, morre torto" - para referir que as pessoas nascem com comportamentos desajustados e que o ambiente, além de não interferir nisto, não pode alterá-lo -; ou “amanhã é dia de branco" - para se referir à atividade laboral e simultaneamente induzir que a pessoa negra não trabalha dignamente -; ou até mesmo em frases repetidas no cotidiano escolar quando a mãe justifica que seu filho não aprende assim como o restante da família, sem sucesso escolar, "porque sofre dos "nervos". Esta mensagem repetida inúmeras vezes e por diferentes canais acaba por ser 
incorporada no autorelato, sem contradição explícita, mas com um efeito interno devastador, que pode levar à imobilidade e à própria inibição de aprendizagem.

A discussão de Carvalho (2004) acerca do empoderamento no campo da saúde colabora em nossas reflexões sobre este tema, pois aponta

a implementação de práticas e processos que valorizem a criação de espaços públicos (rodas e grupos de discussão, colegiados, gestores etc.), que logrem promover a participação dos indivíduos e coletivos na identificação e na análise crítica de seus problemas, visando a elaboração de estratégias de ação que busquem a transformação do status quo. (Carvalho, 2004, p.1093)

Ter a narrativa como ponto de partida ou como metodologia de trabalho fortalece o rompimento com o repetitivo inaudível. Quer seja em uma atividade dual, quer seja em uma atividade grupal, o uso da narrativa como espaço de enunciação e emancipação se compromete com o desenvolvimento humano. Tanto a educação quanto a saúde compromissadas eticamente com o ser humano buscam romper com a opressão, com a submissão. Defendem a discussão de ideias, opiniões e conceitos com vistas à solução de problemas. Se na (con)vivência do poder exercido sobre o outro preconizam-se a obediência, a manutenção, a repetição, na (con)vivência do poder compartilhado, do poder com o outro, preconizam-se o desenvolvimento do pensamento, o sujeito de direitos, da cidadania.

Quando as ações de promoção de saúde não são suficientes, o que fazer? A narrativa poderia ser utilizada também na terapia? Existe alguma outra possibilidade além da contribuição da psicanálise? Dada a extensão destas questões, destacar-se-á a contribuição do enfoque construtivista na psicoterapia.

\section{Narrativa: teoria e terapia}

Os enfoques construtivistas da psicoterapia consideram que mediante a linguagem é posssível configurar múltiplas realidades. Os construtivistas narrativos estão interessados em compreender como a mente integra a experiência e the outorga significado, quer consciente quer inconscientemente. Gonsalves (1992, 1998[1995]) apresenta uma concepção construtivista do inconsciente, diferente da psicanalista e da psicologia profunda. Ele é um exemplo de construtivistas narrativos interessados em compreender como a mente inconsciente ou tácita integra a experiência e atribui significado.

Os terapeutas cognitivos semânticos e construtivistas têm reconhecido cada vez mais o papel das primeiras narrativas e os processos inconscientes na 
psicopatologia. A terapia cognitiva narrativa parte da concepção do sintoma e do transtorno psicológico como resulado de uma incapacidade para dar conta da diversidade de experiências vivenciadas pelo sujeito. Pensemos em alguns dos conceitos relevantes de alguns destes autores. Bruner (2002) destaca o feito da narrativa como instrumento para encontrar o significado da realidade, de maneira particular. Isto é importante porque sabemos que a produção narrativa requer um marco organizado que permita a um sujeito, uma criança neste caso, poder interpretar e entender os acontecimentos que o rodeiam. Mas de quem depende esta "organização"? Esta sistematização depende de mediações conformadas pelos processos psíquicos que intervêm.

Para Guidano (1994), estes processos são particulares, e o sentido guarda uma coerência interna com a própria vida. Porém a própria vida, por mais particular que seja, não está desligada da relação com o outro.

Estas considerações concordam com a ideia da prematuridade da criança ao nascer. Isto faz que sua dependência seja ao outro, ao semelhante, para tudo o que o rodeia. Trata-se da condição de desamparo inicial do ser humano. 0 sentido está estritamente ligado à conjunção eu-outro. Primeiramente está no outro, é o que possibilita a formação do eu - eu me constituo em base com os outros. Portanto, os efeitos da função parental nunca podem construir uma realidade objetiva, como disse Guidano (1994), porque antes está o outro como primeiro constituinte, que simultaneamente se chega aos outros que o antecedem, os outros da cadeia geracional.

Ambos autores, Bruner e Guidano, coincidem na proposição de que a narrativa se vale da linguagem como um meio para conhecer a realidade. Descarta-se a ideia de que a realidade seja um feito objetivo, quando sabemos que a maneira de captar o mundo é realizada irremediavelemente por meio de representações desta realidade. Neste sentido, a representação não é inata, senão que é o efeito da construção progressiva do aparato psíquico. A função narrativa depende da capacidade de representação, mas, de acordo como se estabeleça a constituição psíquica, se articulará o campo representacional.

Estes autores propõem que estas narrativas se constituem em conteúdos preverbais e analógicos, desenvolvidos desde a primeira infância como sequência de imagens. Estas estão organizadas de modo inconsciente e na forma de imagens ou metáforas que conformam esquemas prototípicos. Neste ponto, parece que tanto Bruner (2002) como Guidano (1994) estavam se referindo ao conceito de representação, uma imagem mental constituída na ausência do objeto, uma inscrição no plano inconsciente. A representação permite a criação do inconsciente, reprimido, e é a partir dele que se constitui o eu. Este eu, além de ser uma diferenciação do aparato psíquico, é uma representação de si mesmo 
que permite a autodeterminação, posicionando-se consigo mesmo e com o que rodeia o sujeito.

A partir do descobrimento do semelhante é que se pode ir se apropriando de si mesmo. Os objetos do mundo cobram interesse a partir dos desprendimentos sucessivos com o originário. Os modos de representação primeiros se dão em inscrições. A terapia traria ao consciente estas narrativas prototípicas, e produziria narrativas alternativas, de modo que o sujeito possa atender a novas nuances de suas experiências e construir uma realidade de múltiplos significados. Bem, remete-se, então, ao originário como uma ponte que leve a conhecer sobre esta questão.

A perspectiva narrativa na terapia põe em questionamento as práticas terapêuticas atuais, as quais estão infuenciadas por discursos estruturalistas. Desde a metáfora do texto se propõe uma aproximação à vida das pessoas como histórias e um conjunto de práticas terapêuticas que vão à busca de eventos marginalizados por relatos dominantes na experiência de vida das pessoas, portanto, para favorecer a geração de relatos alternativos que autorizem os conhecimentos e habilidades que os sujeitos têm, para fazer que sua vida se encaminhe de acordo com suas particularidades. (White; Epston, 1993; White, 1995)

Na terapia narrativa, uma das ferramentas utilizadas são os relatos que pemitem "externalizar o problema". Este processo possibilita que as pessoas coisifiquem os problemas. Mediante esta modalidade e por meio da narração, os problemas ou situações conflitivas se convertem em algo que o sujeito pode objetivar. As pessoas referem suas experiências contando histórias, as quais antecedem as práticas. Estas narrações determinam os modos de futuras experiências. Várias proposições podem ser feitas, desde a representação por meio de desenhos ou colagem, ou mesmo a roda de conversa durante a tecelagem de uma tela em grupo, por exemplo.

A ênfase sobre a narração vincula as terapias socioconstrucionistas, tais como a terapia narrativa com as teorias de deconstrução (Reinoso, 2009). 0 processo de desconstrução tem relação com procedimentos que mudam as realidades e as práticas aceitas como verdades, significa a desmontagem do percebido, nesta análise se percebe o que não se oferece explicitamente ao observador. Para Derrida (Goulart, 2003), as palavras não podem expressar tudo o que se pretende ou que se imagina. As lacunas são inevitáveis e sua capacidade de ser modificada a torna conceito incompleto. A verdade do narrado não está no dito ou ouvido, mas na sua incompletude e na possibilidade de desconstrução. 0 uso da narrativa permite uma aproximação aos conflitos e à sintomatolodia porque considera as formas de expressões mais propícias para a infância. Num processo terapêutico 
grupal infantil, pode-se utilizar a contação de estória como ferramenta. Estas estórias podem ser contos de fada tradicionais ou construções coletivas de textos. Estas peças podem ser debatidas ou dramatizadas, enriquecidas pela discussão coletiva e pela elaboração pessoal.

As pespectivas psicoterapêuticas que utilizam a narrativa servem para a intervenção com criança. A intervenção clínica permite uma abordagem junto à criança porque, mediante instrumentos conhecidos como a expressividade oral, por exemplo, determinam os efeitos que geram as condições de carência na contenção subjetiva que envolvem as falhas no psiquismo infantil, restringindo sua capacidade simbólica (Satriano, 2009). Outras áreas de expressividade, além da oral, podem ser exploradas. Pode-se propor como desafio em uma turma a descoberta de outros canais expressivos e oportunizar esta vivência.

A exteriorização dos conflitos e sua abordagem por meio do jogo e da fantasia são motivadoras para a criança e possibilitam trabalhar suas dificuldades. Sabemos da importância de externalizar os problemas através da linguagem. Esta posição terapêutica sustenta que o problema se percebe como algo separado da criança. 0 relato ou a narrativa implicam a apropriação do próprio mal-estar através do sujeito. Ao utilizar-se da máscara, da fantasia ou de fantoches, por exemplo, algumas crianças tornam-se mais desinibidas e conseguem se expressar com menos obstáculos. 0 mediador não precisa se preocupar com a coerência ou a lógica interna, visto que o objetivo maior é o exercício da enunciação e depois da reflexão. Quando a própria criança escolhe seu papel, ou seu personagem, vários aspectos se presentificam nesta ação. Ela pode aprender a lidar com a ansiedade em um nível suportável e intercambiável com seus pares.

Esta posição teórica mantém a ideia de que, ao perceber o problema como algo separado dele, não seja afetada sua própria identidade. De igual forma, ter em conta não somente os aspectos negativos da criança, mas também suas habilidades e qualidades, pode favorecer também que a criança desenvolva um autoconceito mais positivo e realista. Ambos são de suma importância em nossa socieade atual, na qual estatísticas de maus-tratos e abusos psicológicos a crianças são enormes, e grande parte destes correponde a desqualificações da criança por parte de seus pais, familiares e também educadores. Quantos pais e adultos responsáveis por crianças não as tratam pelo nome e sim por apelidos pejorativos, por exemplo, a reação agressiva da criança a este tratamento não significa necessariamente uma elaboração, mas, pelo contrário, ela pode estar se identificando ao que the é atribuído. Quando a criança tem a chance de experimentar a flexibilidade de viver diferentes papeis sociais, de colocar-se em diferentes situações (vividas ou imaginadas), ela tem a oportunidade de organizar-se melhor internamente. A mediação neste momento tem a possibilidade de provocar mudanças positivas e 
incitar o questionamento acerca de quem é, que lugar ocupa e o que deseja.

Por último, consideramos que a terapia narrativa, além de incentivar o desenvolvimento emocional e pessoal adequado e positivo, também é um excelente meio para ajudar a criança em seu desenvolvimento cognitivo, já que, ao se utilizar uma linguagem que the é familiar, a criança se atreverá a relatar sua própria visão do mundo, e o que nele ocorre, e a desenvolver e levar a cabo os planos que the permitam solucionar seus conflitos por seus próprios meios.

Greco (2006 apud Kammerer, 2000) destaca o calor estruturante da lei simbólica que impõe e permite a humanização pulsional. As proibições estruturantes integradas inicialmente na família. A renúncia pulsional deveria levar a uma satisfação de um nível mais alto, condizente com os laços sociais e a vida em comunidade. A sublimação ou humanização da pulsão se refere às pulsões que devem poder satisfazerem-se em novas realizações de desejos, lícitas desta vez. Quando a instituição garante ao sujeito maior consideração frente aos outros e a si mesmo, colabora com o sujeito no aumento do poder sobre sua vida.

Uma instituição, educativa ou terapêutica, que demande renúncias e sublimações pulsionais sem oferecer, como contrapartida, o reconhecimento e os meios para uma autonomia criadora nova, não obterá o que espera. Os jovens se recusarão a integrar a lei simbólica que retorna assim, novamente rechaçada. (Greco, 2006, p. 140) ${ }^{1}$

Para a efetiva contribuição para o processo de humanização, de subjetivação e de emancipação, o uso da narrativa deve considerar a lei simbólica, presente nas regras do jogo, por exemplo. Nestas situações, o sujeito exercita seu respeito frente aos limites que o levariam à descarga pulsional bruta, que pode levar a si mesmo e ao seu grupo à destruição. Contudo, esta proibição não deve ser sinônimo de opressão. Ela deve significar a possibilidade de insurgência de novos direitos e novas formas de viver e conviver, deve ser uma porta para a sublimação e superação. Cada um escreverá sua história e poderá criar diferentes modos de pertença que não sejam alienantes, visto que são mutáveis e negociáveis.

Estas pertenças permanecerão sendo plurais, suporte de laços que integrem os encontros e as ausências, 0 sujeito será o regulador de eventuais conflitos entre estas diversas pertenças. Através delas negociará suas solidariedades sociais ou familiares e experimentará o sentimento de sua identidade cambiante. Estas pertenças negociadas, dado que aportam solidariedades mútuas, não se transformarão em pertenças fusionais, esmagadoras ou redutoras de diferenças pessoais. E a pertença a diferentes grupos sociais é uma maneira de definir a própria identidade. (Greco, 2006, p. 140) ${ }^{2}$

1. Tradução livre.

2. Tradução livre. 
Minayo (1998 apud Vasconcelos; Fontenelle; Nations, 2003) entende a narrativa como capaz de relacionar significado inerente aos atos, às relações e estruturas sociais. Contar histórias implica intencionalidade de modo mais autêntico e com marcas indexadas (referenciadas pelas experiências pessoais e pelos acontecimentos e ações). Por conseguinte, o ato de narrar movimenta o sujeito em direção à saúde e à emancipação.

\section{Considerações}

O estudo teórico da narrativa desenvolvido neste artigo aponta para a possibilidade da construção de uma matriz operatória psicodinâmica comum resultante da reflexão de investigações anteriores de duas pesquisadoras, uma argentina e outra brasileira. A narrativa foi conceituada como uma ferramenta possível de intervenção e pesquisa no campo da educação e saúde.

A revisão teórica mostrou-se coerente e fundamentada na proposição de que trabalhar com o sujeito, com o compromisso de sua emancipação, é um compromisso ético, além de político-ideológico. 0 uso da enunciação, presente na narrativa, é um caminho válido e eficaz para este empreendimento. Esta ferramenta ganha mais força quando os sujeitos em questão estão em uma situação de opressão social, por exemplo, em situação de deficiência, precarização simbólica e/ou risco social, visto que comumente é o grupo enfraquecido no aspecto simbólico e na autoestima.

A narrativa traz a possibilidade e a responsabilidade da assunção do lugar de narrador e quebra com o círculo vicioso do já estabelecido, de ampliar a consciência de si e do entorno, realidade esta fruto da interpretação construída sob influência de conteúdos familiares herdados, da pressão sóciocultural e das vivências singulares. Há espaço para este trabalho tanto no campo da educação quanto na saúde, de modo individual ou grupal.

A narrativa de uma criança é rica em suas características peculiares, que apontam para sua estrutura cognitiva, social e emocional. Ela funciona como portal de desenvolvimento. Não há um patamar final de alcance, a narrativa aponta para uma história que será contada e recontada eternamente. Sua finalidade e riqueza dependerão de diferentes fatores internos e externos. No campo da educação e da saúde o que prevalece é a possibilidade de negociação e de atualização. 


\section{Referências}

BROCKMEIER, Jens, HARRÉ, Rom. Narrativa: problemas e promessas de um paradigma alternativo. Psicologia: Reflexão e Crítica, Porto Alegre, v. 16. n. 3, p. 525-535, 2003. Disponível em: <http://www.scielo.br/pdf/prc/v16n3/v16n3a11. pdf>. Acesso em: mar. 2012.

BRUNER, Jerome. Atos de significação. Porto Alegre: Artmed, 2001. . Realidade mental, mundos possíveis. Porto Alegre: Artmed, 2002.

BRUSCHI, Michel Euclides; GUARESCHI, Neuza Maria de Fátima. A narrativa como escrita dos trabalhos em Construcionismo Social. Anais. XIV Encontro Nacional da ABRAPSO. Tema: Diálogos em Psicologia Social: Epistemológicos, metodológicos, éticos, políticos, estéticos e políticas públicas. 31 de outubro a 03 de novembro de 2007. Universidade do Estado do Rio de Janeiro (UERJ). 2007. Disponível em: <http://www.abrapso.org.br/siteprincipal/anexos/AnaisXIVENA/conteudo/pdf/ trab_completo_275.pdf $>$. Acesso em: set. 2010.

CARVALHO, Sérgio Resende. Os múltiplos sentidos da categoria "empowerment" no projeto de Promoção à Saúde. Cadernos de Saúde Pública. 2004, v. 20, n.4, p. 1088-1095. Disponível em: <http://www.scielo.br/pdf/csp/v20n4/24.pdf>. Acesso em: dez. 2012.

COSTA, Lígia Militz. Ficção e História na perspectiva estruturalista de R. Barthes. Letras. Universidade Federal de Santa Maria. Centro de Artes e Letras. Santa Maria: PPGL. Jul/dez.1993. v. 6, p. 27-31. Disponível em: <http://w3.ufsm.br/ revistaletras/artigo_r6/artigo\%202.pdf>. Acesso em: jun. 2013.

DAMATTA, Roberto. Brasil dois mil: um exercício de profecia. In FERREIRA, M. M.; FERNANDES, T. M.; ALBERTI, S. (Orgs.). História oral: desafios para o século XXI. Rio de Janeiro: Fiocruz / Casa Oswaldo Cruz / CPDOC Fundação Getúlio Vargas, p.23-30, 2000.

DE CONTI, Luciane; SPERB, Tania Mara. A Composição de Narrativas pela Dupla Terapeuta-Paciente: Uma Análise da sua Organização e da sua Sequência de Ações. Psicologia: Reflexão e Crítica, v. 22, n. 1, p. 119-127. 2009. Disponível em: $<$ http://www.scielo.br/pdf/prc/v22n1/16.pdf>. Acesso em: mar. 2011.

DOR, Joel. Introdução à leitura de Lacan, v.1: o inconsciente estruturado como uma linguagem. Porto Alegre: Artes Médicas, 1989.

DUTRA, Elza. A narrativa como uma técnica de pesquisa fenomenológica. Estudos de Psicologia, v. 7, n. 2, p. 371-378. 2002. Disponível em: <http://www.scielo.br/pdf/ epsic/v7n2/a18v07n2.pdf>. Acesso em: set. 2011.

FIORIN, José Luis. As Astúcias da enunciação: as categorias de pessoa, espaço e tempo. São Paulo: Ática. 2002.

GONÇALVES, Óscar. Narrativas del inconsciente. Las terapias cognitivas: regresso 
al futuro. Revista de psicoterapía. p 29-48. v. III. n.12. 1992.

Construtivismo em psicoterapia. Barcelona: Paidós, 1998 loriginal de 1995).

GOULART, Audemaro Taranto. Notas sobre o desconstrucionismo de Jacques Derrida. PUC Minas. Programa de Pós-Graduação em Letras Literaturas de Língua Portuguesa. 2003. Disponível em: <http://www.pucminas.br/imagedb/mestrado_ doutorado/publicacoes/PUA_ARQ_ARQUI20121011175312.pdf?PHPSESSID=6f682 31162773639d99362597576a8e1>. Acesso em: dez. 2012.

GRECO, M. B.. Acerca das identidades e situações: pensamentos sobre a emancipação. Psicologia USP. 2006, v. 17, n.1, p. 125-154. Disponível em: <http:// www.scielo.br/pdf/pusp/v17n1/v17n1a09.pdf>. Acesso em: dez. 2012.

GUIDANO, Vittorio. El si mismo en proceso. Barcelona: Paidós, 1994.

JORGE, Marco Antonio Coutinho. Fundamentos da psicanálise de Freud a Lacan: as bases conceituais. Rio de Janeiro: Jorge Zahar Editor, 2002.

JOUTARD, Phelippe. Desafios à história oral do século XXI. In FERREIRA, M. M.; FERNANDES, T. M.; ALBERTI, S. (Orgs.). História oral: desafios para o século XXI. Rio de Janeiro: Fiocruz / Casa Oswaldo Cruz / CPDOC Fundação Getúlio Vargas, 2000. p. 31-46.

JOVCHELOVITCH, Sandra, BAUER, Martin W. Entrevista narrativa. In: BAUER, M. W., GASKELL, G. Pesquisa qualitativa com texto, imagem e som: um manual prático. Petrópolis: Vozes; p. 90-113, 2002.

MARQUES, Valéria; SATRIANO, Cecília. Processos de subjetivação e precarização simbólica. Boletim Interfaces da Psicologia da UFRRJ - ISSN 1983-5570 Vol. 2, No. 2, Dezembro 2009. Disponível em: <http://www.ufrrj.br/seminariopsi/2009/ boletim2009-2/marques.pdf>. Acesso em: jan. 2013.

. Aplicação do olhar fluido em um estudo sobre a relação entre aprendizagem e contextos de precarização simbólica. Boletim Interfaces da Psicologia da UFRRJISSN 1983-5507 Vol. 3, No 2, p.25-39, Julho - Dezembro de 2010. Disponível em: <http://www.ufrrj.br/seminariopsi/2010/boletim2010-2/marques.pdf>. Acesso em: jan. 2013.

MINAYO, Maria Cecilia S. Saúde e ambiente no processo de desenvolvimento. Ciência e Saúde coletiva. Editorial.; 3(2): p. 4-5, 1998. Disponível em: <http://www. scielo.br/scielo.php?script=sci_arttext\&pid=S1413-81231998000200001\&lng=pt\& nrm=iso>. Acesso em: jul. 2011.

MOTTA, Luiz Gonzaga. A Análise Pragmática da Narrativa Jornalística. XXVIII Congresso Brasileiro de Ciências da Comunicação. Rio de Janeiro, set 2005. Disponível em: <http://galaxy.intercom.org.br:8180/dspace/bitstream/1904/16836/1/R24191.pdf>. Acesso em: jan. 2011.

NUNES, Eduardo Duarte; CASTELLANOS, Marcelo Eduardo Pfeiffer; BARROS, 
Nelson Filice. A experiência com a doença: da entrevista à narrativa. Physis. v. 20, n. 4, p. 1341-1356. 2010. Disponível em: <http://www.scielo.br/pdf/physis/v20n4/ a15v20n4.pdf>. Acesso em: jan. 2011.

PATRON, Sylvie. On the Epistemology of Narrative Theory: Narratology and Other Theories of Fictional Narrative. HYVÄRINEN, M.; KORHONEN, A.; MYKKÄNEN J. (eds.) The Travelling Concept of Narrative. Studies across Disciplines in the Humanities and Social Sciences. Helsinki Collegium for Advanced Studies. p. 118 -133. 2006. Disponível em: < http://www.helsinki.fi/collegium/e-series/volumes/ volume_1/001_09_patron.pdf>. Acesso em: nov. 2010.

REINOSO, Darwin Esteban Murgas. La terapia narrativa como posibilidad subversiva a los discursos de género y poder en la violencia de género. Em Psicopedia Hoy. Actualidad en Psicología y Educación. 2009. Disponível em: <http://psicopediahoy. com/terapia-narrativa-violencia-de-genero/>. Acesso em: dez. 2012.

RUIZ, Alfredo. Conversación con Vittorio Guidano. Anais “Diez Años de PostRacionalismo en Chile". 2007. Disponível em: <http://www.inteco.cl/articulos/015/ texto_esp.htm>. Acesso em: fev. 2013.

SATRIANO, Cecilia Raquel. Importancia del Análisis Textual como Herramienta Para el Análisis Del Discurso. Cinta de Moebio. Revista de Epistemología de Ciencias Sociales. Facultad de Ciencias Sociales, Chile. 2009.

SILVA, Denise Guerreiro Vieira, TRENTINI, Mercedes. Narrativas como técnica de pesquisa em enfermagem. Revista Latinoamericana de Enfermagem. n.10, 2002, p. 423-432. Disponível em: <http://www.scielo.br/pdf/rlae/v10n3/13352.pdf>. Acesso em: dez. 2010.

SOUZA, Marcelo Freire Pereira. Narrativa hipertextual multimídia: um modelo de análise. Santa Maria: FACOS, 2010. Disponível em: <http://acervo-digital.espm. br/e-books/287424.pdf>. Acesso em: fev. 2011.

VAN DIJK, Teun. Grammaires textuelles et structures narratives, Em Essais de sémiotique narrative et textuelle. Larousse: França, 1973.

. Discurso e poder. São Paulo: Contexto. 2008.

VASCONCELOS, Geison Lira; FONTENELLE, Ana. Maria Catrib; NATIONS, Marilyn K. A narrativa na pesquisa social em saúde: perspectiva e método. Revista Brasileira em Promoção de Saúde (RBPS). v. 16, n. 1 / 2, 2003, p. 59-66. Disponível em: <http:// redalyc.uaemex.mx/pdf/408/40816211.pdf>. Acesso em: ago. 2009.

WHITE, Michel. La perspectiva narrativa en la terapia. Em Reescribir la vida. Barcelona: Gedisa. 1995.

; EPSTON, David. Medios narrativos para fines terapéuticos. Barcelona: Paidós. 1993. 
Recebido em julho de 2013

Aprovado em novembro de 2013

Valéria Marques de Oliveira é doutora em Psicologia pela Universidade Federal do Rio de Janeiro e pós-doutora em Educação pela Universidade do Estado do Rio de Janeiro. É professora da Universidade Federal Rural do Rio de Janeiro (UFRRJ), Instituto de Educação, Departamento de Psicologia. E-mail: valeriamarquesa ufrrj.br

Cecilia Raquel Satriano é doutora em Psicologia pela Universidad Nacional de Rosario e professora pesquisadora da Universidad Nacional de Rosario (UNR Argentinal. E-mail: ceciliasatrianolfibertel.com.ar 